\title{
A numerical study on the high-velocity impact behavior of pressure pipes
}

\author{
Zhen-yu WANG ${ }^{\dagger 1}$, Yang ZHAO ${ }^{2,3}$, Guo-wei MA ${ }^{3}$, Zhi-guo $\mathrm{HE}^{2}$ \\ ( ${ }^{1}$ College of Civil Engineering and Architecture, Zhejiang University, Hangzhou 310058, China) \\ $\left({ }^{2}\right.$ Ocean College, Zhejiang University, Hangzhou 310058, China) \\ $\left({ }^{3}\right.$ School of Civil, Environmental and Mining Engineering, The University of Western Australia, Crawley, WA 6009, Australia) \\ ${ }^{\dagger} E-m a i l: w z y u @ z j u . e d u . c n$
}

Received May 19, 2015; Revision accepted Dec. 28, 2015; Crosschecked May 9, 2016

\begin{abstract}
Pressure pipes are widely used in modern industry with some in potentially dangerous situations of explosion and impact. The security problems of these pipes when subjected to impact have attracted a lot of attention. A non-linear numerical model has therefore been developed to investigate the dynamic behavior of pressure pipes subjected to high-velocity impact. A high strain rate effect on the pipe response is considered here and the fluid and pipe interaction is modeled to include the coupling effect between the deformation of the pipe and its internal pressure. Low-velocity and high-velocity impact experimental results are used to verify the numerical model, and a reasonable agreement between the numerical and experimental results has been achieved. The effects on the dynamic behavior of the pipes of the nose shape of the projectile, the diameter of the spherical projectile, and the pipe wall thickness and internal pressure, are investigated quantitatively. During high-velocity impacts, the increase of pressure in the pipes decreases their resistance to perforation. A rise in internal pressure increases the elastic resistance of the pipes toward impacts without crack formation.
\end{abstract}

Key words: Pressure pipes, High-velocity impact, Fluid-structure interaction, Impact resistance, Numerical simulation http://dx.doi.org/10.1631/jzus.A1500112 CLC number: TU333

\section{Introduction}

Pipes are extensively used in the petrochemical industry, for example, in offshore oil platforms and refinery and oil storage terminals, to convey gases and liquids under high pressure. They are often used in potentially dangerous situations as well as in situations of probable accident, such as leakage, fire, and explosion. Furthermore, one of these types of accident often causes another. For example, when a

\footnotetext{
" Project supported by the Australian Research Council Linkage Projects, the National Natural Science Foundation of China (Nos. 51279180, 51079127, 51579221, and 51179171), the National Basic Research Program (973 Program) of China (No. 2013CB035901), and the Public Welfare Technology Application Research Project of Zhejiang Province (No. 2013C33043), China

(D) ORCID: Zhen-yu WANG, http://orcid.org/0000-0003-4575-3754 (C) Zhejiang University and Springer-Verlag Berlin Heidelberg 2016
}

pressure pipe is impacted by high-velocity free-flying projectiles caused by an explosion, the perforation and cracking of the pressure pipe may result in a subsequent leakage, fire and/or explosion leading to a yet more serious catastrophe. Thus, study of highvelocity impact behavior of pressure pipes, especially those containing hazardous fluids, is necessary and has significant implications (Zhao et al., 2014).

NPS is a North American set of standard sizes for pipes used for high or low pressures and temperatures (ASME, 2004), and diameter nominal $(\mathrm{DN})$ is a European designation equivalent to NPS. In the ASME code for pressure piping, pressure includes the design pressure, maximum operating pressure, maximum allowable operating pressure, maximum allowable test pressure, standard service pressure, etc. (ASME, 2007). The pressure in a pipe system is determined by the materials and locations involved. 
Much work has been done in the past few decades on the subject of pipes subjected to impact loads (Corbett et al., 1990; Jones and Shen, 1992; Jones and Birch, 1996; 2010; Liu and Francis, 2004; Nishida and Tanaka, 2006; Lu et al., 2007; Yang et al., 2009; Shah, 2011). Most of the early pipe impact studies focused on empty pipes. Jones and Shen (1992) studied, both by experiment and by theoretical analysis, fully clamped empty mild steel pipelines subjected to lateral impact loads. Corbett et al. (1990) carried out an experimental investigation into the perforation of steel tubes of various diameters struck by hemispherically-tipped projectiles. The effects, on perforation and failure modes, of projectile mass, projectile nose radius, and the means of target support were investigated.

More researchers have paid attention to pressurized pipes filled with a variety of media. Experimental study is the most popular method for investigating the dynamic behavior of pressure pipes. Jones and Birch (1996) conducted a series of low-velocity impact tests on pressure pipes to investigate the influence of internal pressure. The pipes were fully clamped and were impacted laterally by a rigid wedge indenter. The results revealed that smaller impact velocities caused permanent inelastic deformations of the pipes but larger velocities breached their integrity immediately underneath the indenter or at a support. Chen and Shen (1998) conducted a further experimental study based on the test of Jones and Birch (1996) and obtained the threshold value of initial impact energy for causing the onset of material rupture. Lu et al. (2007) investigated the dynamic response and damage of water-filled pressure pipes by a series of experiments. The perforation failure modes and corresponding critical impact energies were obtained from tests. In addition, the test results indicated a significant influence of water pressure on the critical perforation energy. Nishida and Tanaka (2006) conducted an experimental study on waterfilled aluminum tubes subjected to a steel spherical projectile. The effects of the steel projectile and material properties on the tubes' cracking and perforation were investigated. The test result revealed that the ballistic velocity was reduced by the addition of water in the tube. In Nishida and Tanaka (2006)'s study, tubes made of Aluminium $6063 \mathrm{~T} 3$ and Aluminium $6063 \mathrm{H} 18$ were used, and the effect of strain rate was ignored.
Little theoretical modeling has been conducted to quantitatively investigate the deformation of pressure pipes subjected to impact loads. Liu and Francis (2004) presented a quasi-static analysis of pressurized pipelines subjected to an external impact. Their analysis was based on the assumption of a simple, rigid, and perfectly plastic deformation model, and obtained the relationship between the external denting force and the maximum dent depth. Jones and Birch (2010) extended the theoretical analysis of Jones and Shen (1992) and used it in pressure pipes subjected to an impact load. These theoretical models are based on quasi-static and low-velocity impacts and, because of fluid-structure interaction and penetration effects, it is difficult to use them to analyze pressure pipes subjected to high-velocity impacts. Therefore, numerical simulation is an alternative method for investigating this complex problem.

Numerical simulation is a convenient way to gain a deep insight into some explosion and impact problems, which is difficult to gain using theoretical modeling and experimental techniques. Yang et al. (2009) used an explicit finite element (FE) method to simulate the pipe-on-pipe impact event. The numerical result was compared with experimental result and showed that numerical simulations successfully predicted the dynamic plastic behavior of impact pipes. The simulation of Jones et al. (1992) is based on empty pipes. For pressure pipes, Shah (2011) simulated how a water-filled pipe is impacted under orthogonal and oblique configurations using $\mathrm{FE}$ and smooth particle hydrodynamics (SPH) methods coupled together. Results revealed that SPH successfully modeled fluid-structure interaction during impact on a water-filled pipe and showed a good agreement with the experimental result. In Shah (2011)'s study, the impact velocity is a low velocity at $6.71 \mathrm{~m} / \mathrm{s}$. When the target is subjected to high velocity (more than $100 \mathrm{~m} / \mathrm{s}$ ) impact, the projectile penetrates or perforates the target. Many studies have been conducted on plate penetration (Ben-Dor et al., 2005), including some numerical methods (Børvik et al., 1999; 2002). The results showed that numerical simulation is able to describe the dynamic behavior of plates subjected to high-velocity impact loads. However, according to our knowledge, relatively little numerical modeling research has been carried out on perforation of the pressure pipes because most of the studies on pressure 
pipes subjected to impact loads have been conducted assuming lower velocities. Numerical modeling of a pressured pipe subjected to impact, especially at highvelocities, should take the fluid-structure interaction, penetration, and strain rate effects into account. A high-velocity impact may trigger leakage, fire, and explosion events for pressure pipes and few papers dealing with such problems have appeared in the open literature.

This paper presents the findings of a numerical investigation on the dynamic behavior of the pressure pipes subjected to high-velocity impact loads. In the simulation, the Johnson-Cook model is used to simulate the dynamic behavior of steel, and surfacebased cavities are used to simulate the coupling between the pipe and the gas pressure. The experimental results of Jones and Birch (1996) are used to verify the numerical model and give a satisfactory agreement. In addition, the effects of internal pressure of pipes, pipe wall thickness, projectile mass, and projectile nose shape and size are explored. The results of this study reveal the behavior of pressure pipes subjected to high-velocity impact loads and are helpful for the blast-resistant design of pressure pipes for environments with explosion risk.

\section{Governing equations}

The stress state of a pressure pipe can be analyzed by axial stress, radial stress, and circumferential stress. The axial stress is present only in the end cap condition and is expressed as

$$
\sigma_{x}=\frac{P D_{\mathrm{i}}^{2}}{D_{\mathrm{o}}^{2}-D_{\mathrm{i}}^{2}},
$$

or

$$
\sigma_{x}=\frac{P D_{\mathrm{o}}}{4 t}\left[\frac{1-4 \frac{t}{D_{\mathrm{o}}}+4\left(\frac{t}{D_{\mathrm{o}}}\right)^{2}}{1-\frac{t}{D_{\mathrm{o}}}}\right],
$$

where $P$ is the inner pressure, $D_{\mathrm{i}}$ is the inner pipe diameter, and $D_{\mathrm{o}}$ is the outer pipe diameter; $t$ is the thickness of the pipe wall and can be expressed as

$$
t=\frac{D_{\mathrm{o}}-D_{\mathrm{i}}}{2}
$$

The radial stress can be calculated by

$$
\sigma_{r}(r)=\frac{P D_{\mathrm{o}}}{4 t} \frac{D^{2}(r)-D_{\mathrm{o}}^{2}}{D^{2}(r)}\left[\frac{1-4 \frac{t}{D_{\mathrm{o}}}+4\left(\frac{t}{D_{\mathrm{o}}}\right)^{2}}{1-\frac{t}{D_{\mathrm{o}}}}\right],
$$

and the circumferential (or hoop) stress is given by

$$
\sigma_{h}(r)=\frac{P D_{\mathrm{o}}}{4 t} \frac{D^{2}(r)+D_{\mathrm{o}}^{2}}{D^{2}(r)}\left[\frac{1-4 \frac{t}{D_{\mathrm{o}}}+4\left(\frac{t}{D_{\mathrm{o}}}\right)^{2}}{1-\frac{t}{D_{\mathrm{o}}}}\right] .
$$

The greatest circumferential stress occurs near the inner surface of the pipe and can be presented as

$$
\sigma_{h_{\max }}=\frac{P D_{\mathrm{o}}}{2 t}\left[\frac{1-\frac{t}{D_{\mathrm{o}}}+2\left(\frac{t}{D_{\mathrm{o}}}\right)^{2}}{1+\frac{t}{D_{\mathrm{o}}}}\right]
$$

The stress state is calculated by taking the state of natural service for a pressure pipe into account. When the pressure pipe is subjected to an impact load, the initial stress state of the pipe can be calculated by the above equations.

\section{Material model and methods}

\subsection{Johnson-Cook model}

The Johnson-Cook model (Johnson and Cook, 1983 ; 1985) is a phenomenological-based plasticity model that deals with the behavior of metals due to strain hardening, strain-rate hardening, and thermal softening. The flow stress from the Johnson-Cook model is expressed as

$$
\sigma=\left(A+B \varepsilon^{n}\right)\left(1+C \ln \dot{\varepsilon}^{*}\right)\left[1-\left(T^{*}\right)^{m}\right]
$$


where $A, B, C, n$, and $m$ are material parameters, $\varepsilon$ is the equivalent plastic strain, $\dot{\varepsilon}^{*}=\dot{\varepsilon} / \dot{\varepsilon}_{0}$ is the nondimensional strain rate, $\dot{\varepsilon}$ is the equivalent plastic strain rate, $\dot{\varepsilon}_{0}$ is a reference strain rate, and $T^{*}$ is the non-dimensional temperature defined as

$$
T^{*}=\left(T-T_{0}\right) /\left(T_{\text {melt }}-T_{0}\right), \quad T_{0} \leq T \leq T_{\text {melt }},
$$

where $T$ is the current temperature in Kelvin, $T_{0}$ is the room temperature, and $T_{\text {melt }}$ is the melting point temperature (Gupta et al., 2006). In Eq. (7), the first bracket represents an exponential strain hardening model, while the second and third brackets concern the effects of strain rate and temperature, respectively.

Johnson and Cook (1985) developed a dynamic failure model which is suitable for high-strain-rate deformation of metals. This failure model is based on the value of the equivalent plastic strain at element integration points (Zhao et al., 2014). The damage parameter $D$ is calculated for each element and is defined by

$$
D=\sum \frac{\Delta \varepsilon}{\varepsilon^{\mathrm{f}}}
$$

where $\Delta \varepsilon$ is an equivalent plastic strain during an integration step and $\varepsilon^{\mathrm{f}}$ is the strain at failure. The fracture of the element is assumed to occur when $D$ $=1.0$. The failure strain can be given by

$$
\varepsilon^{\mathrm{f}}=\left[D_{1}+D_{2} \exp \left(D_{3} \sigma^{*}\right)\right]\left(1+D_{4} \ln \dot{\varepsilon}^{*}\right)\left(1+D_{5} T^{*}\right),
$$

where $D_{1}-D_{5}$ are failure parameters identified from tests and $\sigma^{*}$ is the dimensionless press-stress ratio, which is defined as $\sigma^{*}=\sigma^{\mathrm{m}} / \bar{\sigma}$, where $\sigma^{\mathrm{m}}$ is the average of the three normal stresses, and $\bar{\sigma}$ is the von Mises equivalent stress (Pantalé et al., 2004). The first set of brackets in Eq. (10) follows the form presented by Hancock and Mackenzie (1976) and indicates that the strain to fracture decreases as the hydrostatic tension increases. The second and third sets of brackets represent the effect of strain rate and temperature, respectively (Johnson and Cook, 1985).

\subsection{FE modeling of gas-filled pipes}

\subsubsection{Surface-based fluid cavities}

When a gas-filled pipe is subjected to an impact load, the response of the pipe depends not only on the external impact but also on the internal pressure exerted by the gas, which is affected by the deformation of the pipe. Under the Abaqus environment, the surface-based fluid cavity, which behaves like a liquid-filled or gas-filled structure, is selected to model the coupling between the deformation of the pipe and the gas pressure. The surface-based fluid cavity capability does not require the definition of fluid elements and therefore supersedes the elementbased hydrostatic fluid cavity capability in functionality (ABAQUS, 2010). The important process in this method is to define the boundary of the fluid cavity, which is the solid-fluid interface. When the boundary is specified, the volume of the fluid is ascertained. If the boundary of the fluid cavity changes, the volume will change with it, affecting the state of the fluid, such as pressure, density, and temperature. Conversely, changes to the fluid state will also affect the boundary of the cavity. The solid-fluid interface, therefore, plays a significant role in the surface-based fluid cavities method.

\subsubsection{Modeling procedure for the pipe}

The pre-processor ABAQUS-CAE, used to generate the input file, does not support surface-based fluid cavities. Therefore, the input file which is generated by CAE should be edited to add the surface-based fluid cavities. The gas-filled pipes can be modeled with the following steps:

1. Specifying the boundary of the fluid cavity. The fluid cavity must be completely enclosed by FEs and the pipe in this simulation is modeled as a tube which is closed at both ends. The fluid cavity is defined as a closed surface composed of the inner surfaces of the pipe. The volume of fluid is equal to the volume surrounded by the closed surface.

2. Specifying the cavity reference node. The reference node is an important node used to identify the fluid cavity. It has a single degree of freedom representing fluid pressure inside the cavity. As shown in Fig. 1, the reference node should not be connected to any elements in the model. In this simulation the reference node is an arbitrary independent point inside the pipe. 
3. Defining the ambient conditions and the initial conditions for the fluid cavity. The ambient conditions refer to the ambient pressure and temperature. Generally, the atmospheric pressure and air temperature can be regarded as the ambient pressure and temperature. The ambient conditions do not contribute to the loading of the pipe. The initial conditions refer to the temperature and the pre-pressure in the pipe.

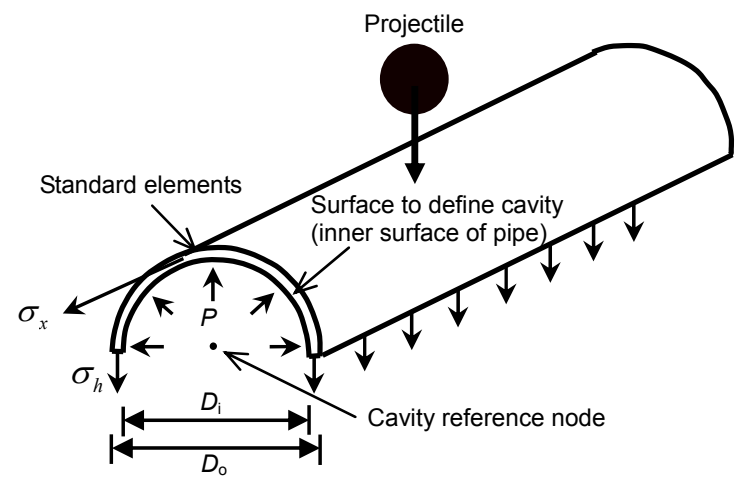

Fig. 1 Schematic diagram of half of a pressure pipe impacted by a projectile

4. Defining the fluid cavity behavior in the pipe. The fluid cavity behavior governs the relationship between the temperature, volume, and inner pressure. As natural gas is a hydrocarbon gas mixture consisting primarily of methane with little of any other gas, we use the gas properties of methane itself. In this simulation, methane is modeled as an ideal gas and the equation of state is given as

$$
\tilde{p}=\rho R\left(\theta-\theta^{\mathrm{Z}}\right)
$$

where $\tilde{p}$ is the absolute pressure, $\rho$ is the gas density at current temperature and pressure, $R$ is the specific gas constant, $\theta$ is the current temperature, and $\theta^{Z}$ is absolute zero on the temperature scale being used (Rezaei et al., 2011). When the pipe is subjected to high-velocity impact, it is a rapid event and can be assumed to be an adiabatic process; therefore, the heat capacity at constant pressure must be specified. The constant pressure heat capacity $c_{\mathrm{p}}$ can be calculated by

$$
c_{\mathrm{p}}=\tilde{c}_{\mathrm{p}} / \mathrm{MW},
$$

where MW is the molecular weight of the gas, and $\tilde{c}_{\mathrm{p}}$ is the constant pressure molar heat capacity. Based on the Shomate equation, the constant pressure molar heat capacity $\tilde{c}_{\mathrm{p}}$ can be defined as (ABAQUS, 2010)

$$
\begin{aligned}
\tilde{c}_{\mathrm{p}}= & \tilde{a}+\tilde{b}\left(\theta-\theta^{\mathrm{Z}}\right)+\tilde{c}\left(\theta-\theta^{\mathrm{Z}}\right)^{2} \\
& +\tilde{d}\left(\theta-\theta^{\mathrm{Z}}\right)^{3}+\frac{\tilde{e}}{\left(\theta-\theta^{\mathrm{Z}}\right)^{2}}
\end{aligned}
$$

where $\tilde{a}, \tilde{b}, \tilde{c}, \tilde{d}$, and $\tilde{e}$ are gas constants.

In this simulation, the pipe model is generated by ABAQUS-CAE and then the input file is written. The surface-based fluid cavities are added to the input file by key words. The key words for the initial conditions are 'INITIAL CONDITIONS, TYPE=FLUID PRESSURE' and 'INITIAL CONDITIONS, TYPE= TEMPERATURE' which means the initial fluid pressure and the initial temperature, respectively. Similarly the key words for the ambient conditions are 'AMBIENT PRESSURE' and 'AMBIENT TEMPERATURE' meaning the ambient pressure and the ambient temperature, respectively. The fluid cavity behavior is defined by the key words 'CAPACITY' and 'MOLECULAR WEIGHT'. The parameters for key word 'CAPACITY' are the gas constants $\tilde{a}, \tilde{b}, \tilde{c}, \tilde{d}$, and $\tilde{e}$, and the parameter for key word 'MOLECULAR WEIGHT' is the molecular weight of the gas (Zhao et al., 2014).

\subsection{Elements and contact modeling}

In this study, pipes were impacted laterally by a rigid missile at their mid-span. The 4-node shell element (S4R) with an hourglass-controlled reduced integration formulation was used to model the pipe. The missiles were treated as rigid bodies, and three different element types were used to model the impact missile. The spherical missile was modeled with 8-node and 6-node linear bricks, reduced integration with hourglass control elements C3D8R and C3D6R, and the $90^{\circ}$ conical missile and blunt missile were both modeled with a 10-node modified tetrahedron element (C3D10M). Surface-based fluid-filled cavities were used to simulate coupling between the deformation of the pipe and the gas pressure. A 'Hard' contact is used to model the interactions between the projectile and the pipe wall. This 'Hard' contact uses 
the penalty contact enforcement in an Abaqus/ Explicit analysis. The 'spring' stiffness that relates the contact force to the penetration distance is chosen by Abaqus/Explicit to represent the hard penalty contact so that the effect on the time increment becomes minimal, although the allowed penetration is insignificant in most analyses.

\section{Verification of the model}

Jones and Birch (1996) performed a series of tests on empty and pressurized pipes subjected to impact loads. The pipe specimens in the tests were all fully clamped and were struck by a $21.5-\mathrm{kg}$ wedgeshaped indenter at the mid-span and one-quarter-span positions. The cold-drawn mild steel pipes all had a 60-mm outside diameter and $1.7-\mathrm{mm}$ wall thickness, and were fully clamped across a $600-\mathrm{mm}$ span. The uniaxial yield stress of the pipes was $710 \mathrm{MPa}$, the ultimate tensile stress was $823 \mathrm{MPa}$, and the uniaxial rupture strain was $6 \%-7 \%$. Four different internal pressures of $0,6.63,9.93$, and $13.27 \mathrm{MPa}$ were used in the tests. Three major failure modes were revealed in the test of pressurized pipes: large inelastic deformations and denting of the cross section, the local failure at the indenter point, and the failure of the pipelines at the fully clamped supports. Rosenberg and Forrestal (1988) conducted a series of highvelocity impacts to study the residual velocity and ballistic limit for conical-nosed rods perforating ductile plates at normal incidence. The targets were 6060-T6 aluminum square plates, and the projectiles were conical-nosed rods.

To verify the numerical model of the gas-filled pipes, the numerical simulations of tests done by Jones and Birch (1996) are performed using Abaqus for samples with the first two failure modes, i.e., the denting of the cross section and local failure at the indenter point. Figs. 2 and 3 are the comparisons of experimental and finite element analysis (FEA) results for empty and pressurized pipes. As shown in Figs. 2 and 3, the abscissa is the impact velocity of the indenter and the ordinate is the permanent transverse displacement $\left(W_{\mathrm{f}}\right)$ of the pipe. The error is calculated by dividing the difference between the experimental results and the FEA results. The average errors of FEA results for empty pipes and pressurized pipes are
$7.53 \%$ and $-1.25 \%$, respectively. Simulating the impact problem is a complicated matter, with numerous factors affecting the results of the experiment. For empty pipes, as shown in Fig. 2, FEA results slightly overestimate the transverse displacements as compared to the experimental results. As shown in Fig. 3, comparison of the experimental results and the FEA results for pressurized pipes shows a better agreement. It is, therefore, acceptable as all the errors are less than $10 \%$. The test results by Rosenberg and Forrestal (1988) were used to verify the numerical models of high-velocity perforation. The aluminum plates impacted by arrowhead projectiles were simulated by Abaqus. The strain rate effect of aluminum plates was considered using the Johnson-Cook model. Fig. 4 is the comparison of the experimental results and FEA results for high-velocity impact. It can be seen that the numerical results predict the residual velocity well compared with the test results. The above results demonstrate that the numerical model in

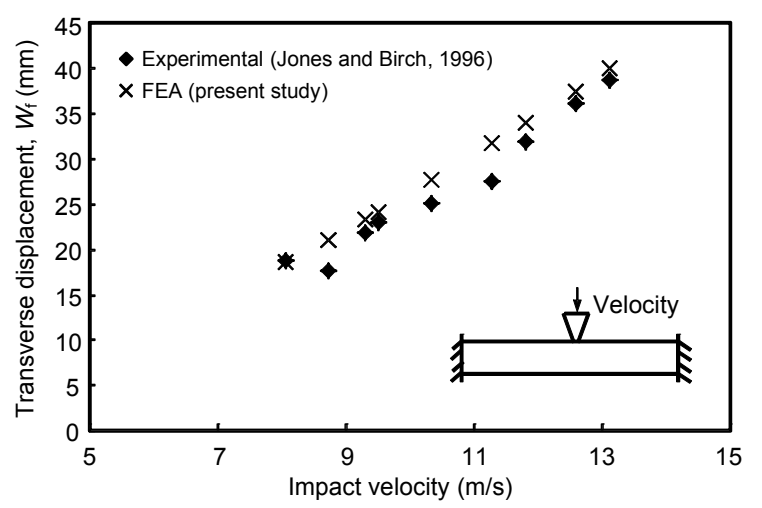

Fig. 2 Comparison of the experimental results and the FEA results for empty pipes

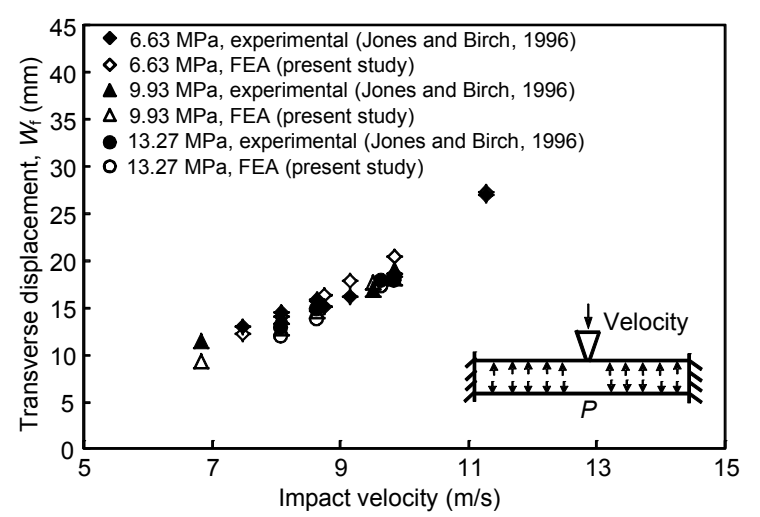

Fig. 3 Comparison of the experimental results and the FEA results for pressurized pipes 
this study is accurate in simulating empty pipes and pressurized pipes subjected to low-velocity and highvelocity impact loads.

\section{Results and discussion}

In this study, steel pipes with a 219.08 -mm outer diameter (NPS 8), a 2000-mm length, and various wall thicknesses, subjected to high-velocity impact, were simulated in Abaqus. Both ends of the pipes were closed and fully clamped, and the closed ends were prevented from moving in the axial direction. Fig. 5a is a schematic diagram of such a pipe impacted by a spherical missile. The material parameters of the gas and steel are shown in Tables 1 and 2.

Figs. $5 \mathrm{~b}-5 \mathrm{~d}$ show the indentation, cracking, and perforation of the target pressure pipes by a spherical projectile at various initial impact velocities. These plots clearly demonstrate that the numerical model qualitatively captures the overall physical behavior of the pipes subjected to an impact load. When the pipe is subjected to impact loads, the dynamic behavior of the pipe is influenced by various parameters, such as the thickness of the pipe wall, the shape and diameter of the nose of the spherical missile, and the internal pressure of the pipe.

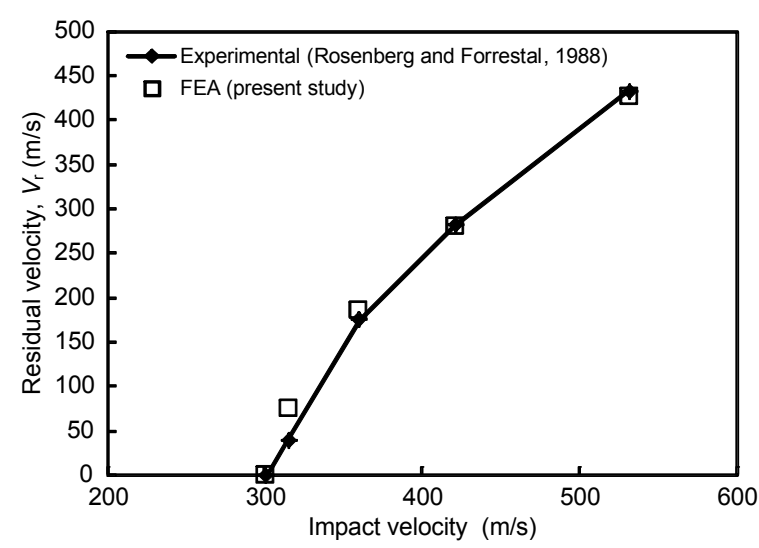

Fig. 4 Comparison of the experimental results and the FEA results for high-velocity impact
Table 2 Material properties of 4340 steel (Johnson and Cook, 1985)

\begin{tabular}{clc}
\hline & Parameter & Value \\
\hline & Density $\left(\mathrm{kg} / \mathrm{m}^{3}\right)$ & 7800 \\
Mechanical & Poisson's ratio, $v$ & 0.3 \\
parameter & Elastic modulus, $E(\mathrm{GPa})$ & 210 \\
& Melting temperature $(\mathrm{K})$ & 1793 \\
\hline & $A(\mathrm{MPa})$ & 792 \\
& $B(\mathrm{MPa})$ & 510 \\
& $n$ & 0.26 \\
& $C$ & 0.014 \\
Johnson-Cook & $m$ & 1.03 \\
model constant & $D_{1}$ & 0.05 \\
& $D_{2}$ & 3.44 \\
& $D_{3}$ & -2.12 \\
& $D_{4}$ & 0.002 \\
& $D_{5}$ & 0.61 \\
\hline
\end{tabular}

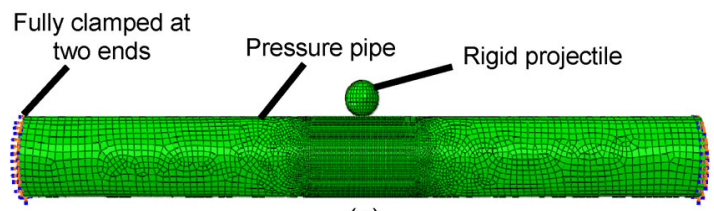

(a)

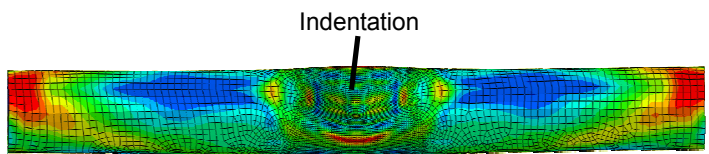

(b)

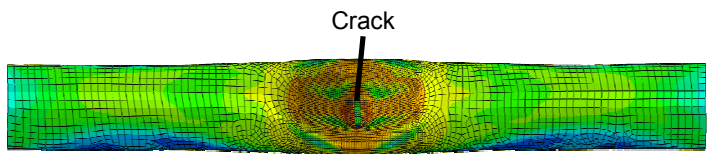

(c)

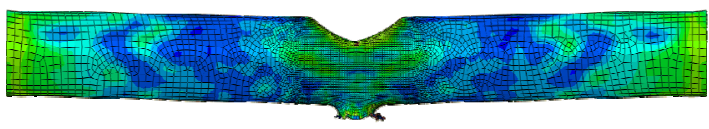

(d)

Fig. 5 Schematic diagram of a pressure pipe impacted by a rigid spherical projectile and three failure modes

(a) Undamaged pressure pipe; (b) Failure mode of indentation;

(c) Failure mode of crack; (d) Failure mode of perforation

Table 1 Properties of methane (Chase, 1998)

\begin{tabular}{cccccccc}
\hline Gas & MW & $\tilde{a}$ & $\tilde{b}\left(\times 10^{-3}\right)$ & $\tilde{c}\left(\times 10^{-6}\right)$ & $\tilde{d}\left(\times 10^{-9}\right)$ & $\tilde{e}\left(\times 10^{6}\right)$ & $\theta(\mathrm{K})$ \\
\hline Methane & 0.016 & -0.703029 & 108.4773 & -42.52157 & 5.862788 & 0.678565 & $298-1300$ \\
\hline
\end{tabular}




\subsection{Influence of pipe wall thickness}

The thickness of the pipe plays an important role in certain diameter pressure pipes subjected to impact loads. Fig. 6 plots the velocity of missile versus time for various pipe wall thicknesses. In this study, the size of the pipe is NPS 8 . The gas pressure of the pipe is $1.8 \mathrm{MPa}$, the diameter of the spherical projectile is $100 \mathrm{~mm}$, and the impact velocity is $200 \mathrm{~m} / \mathrm{s}$. As shown in Fig. 6, for smaller thicknesses of the pressure pipe wall, such as 2.00 and $2.77 \mathrm{~mm}$, the projectiles perforate the pressure pipes easily, while for greater wall thicknesses, such as 3.76, 6.35, 7.04, and $8.18 \mathrm{~mm}$, the projectile rebounds and its velocity becomes negative. It is clear from the results that with the increase of wall thickness the impact-resistance capacity of the pipe increases.

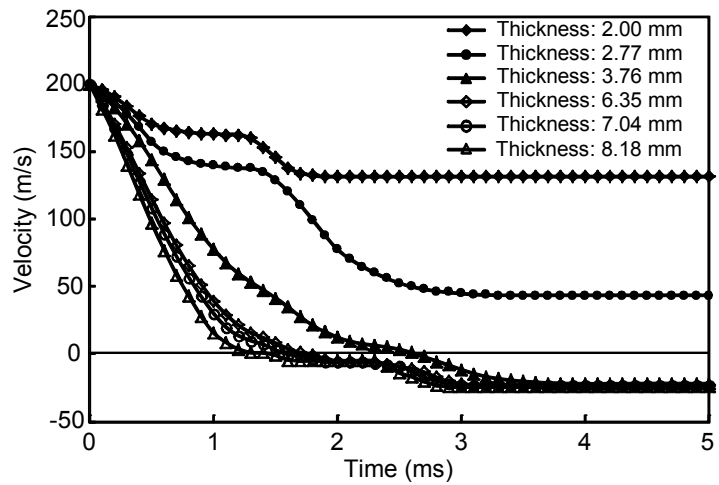

Fig. 6 Velocity of missile over time for various pipe wall thicknesses $(P=1.8 \mathrm{MPa})$

\subsection{Influence of missile nose shape}

Fig. 7 depicts the projectile velocity and displacement over time when the pressure pipes are subjected to three different nose-shaped missiles. The gas pressure of the pipe is $1.8 \mathrm{MPa}$ and the masses of the three missiles are all around $4 \mathrm{~kg}$. The pressure pipes are struck by the missiles at impact velocity of $250 \mathrm{~m} / \mathrm{s}$. It can be seen from Fig. 7 that the conical missile and the spherical missile perforate the pipes, and their velocities decrease. From the velocity curve of the conical missile and the spherical missile, two obvious descending stages mean that the two pipe walls (front pipe wall and back pipe wall) decrease the velocity of the projectiles when they perforate the pipe. For the blunt nose-shaped missile, the velocity decreases over time and then turns negative after
$0.28 \mathrm{~ms}$. This means the projectile with the blunt nose bounces back. It also can be seen from the curves of the missile displacement that the displacement of conical and spherical projectiles increases almost linearly while the displacement of the blunt-shaped projectile reaches its peak value at $0.28 \mathrm{~ms}$ and then decreases. It is obvious that it is easier for a projectile with smaller contact area to perforate the pipes.

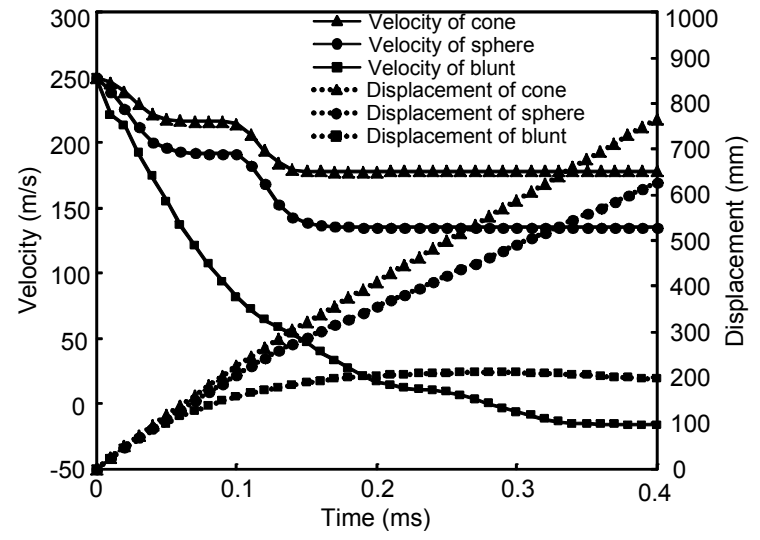

Fig. 7 Velocity and displacement of missile over time for various shaped projectiles $(P=1.8 \mathrm{MPa})$

\subsection{Influence of diameter of spherical missiles}

Figs. 8 and 9 demonstrate the influence of projectile size. The pressure pipe with an internal pressure of $1.8 \mathrm{MPa}$ was impacted by four spherical projectiles of different diameters. The diameters of the spherical projectiles were $50,75,100$, and $125 \mathrm{~mm}$, respectively. Fig. 8 is the FEA results of impact for steel pressure pipes. As impact velocity increases, dent depths will increase until cracks form in the pipe, resulting in leakage. The crack limit velocity represents an impact velocity at which the pipe begins to leak. A broken line is obtained by linking crack limit velocities of different projectile diameters. As indicated by the broken line, the crack limit velocities for pressure pipes decrease as the diameter of the projectile increases. Fig. 9 depicts velocity and momentum curves of missiles in relation to time for various projectile diameters. The time history curves for four sizes of spherical projectiles with impact velocities all of $300 \mathrm{~m} / \mathrm{s}$ and two distinct sizes of spherical projectiles with impact momentums both of $200 \mathrm{~kg} \cdot \mathrm{m} / \mathrm{s}$ are shown. Fig. 9 shows that the projectiles with 75,100 , and $125 \mathrm{~mm}$ diameters perforate the pipes while the 
projectile with $50 \mathrm{~mm}$ diameter bounces back. It is obvious that it is easier for larger spherical projectiles to perforate the pipes because of their larger mass and larger momentum. However, the curves of momentum show that when the momentum of the projectiles is equal, the smaller projectile perforates the pipes more easily because of its smaller contact area.

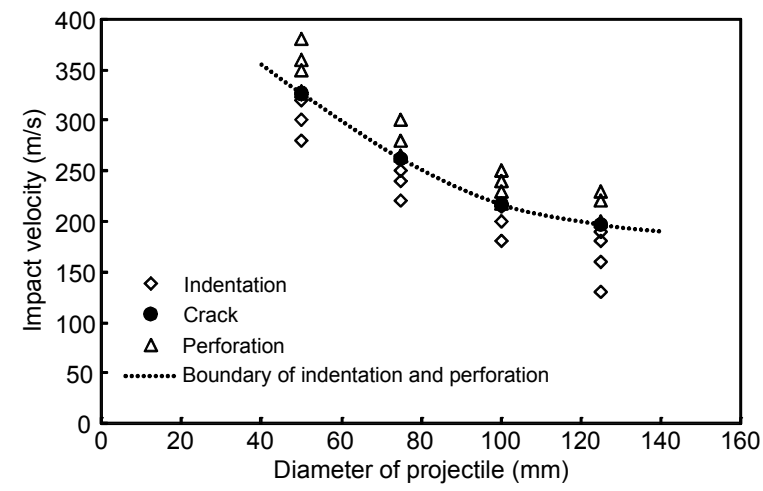

Fig. 8 Crack limit velocities of pressure pipes for different projectile diameters $(P=1.8 \mathrm{MPa})$

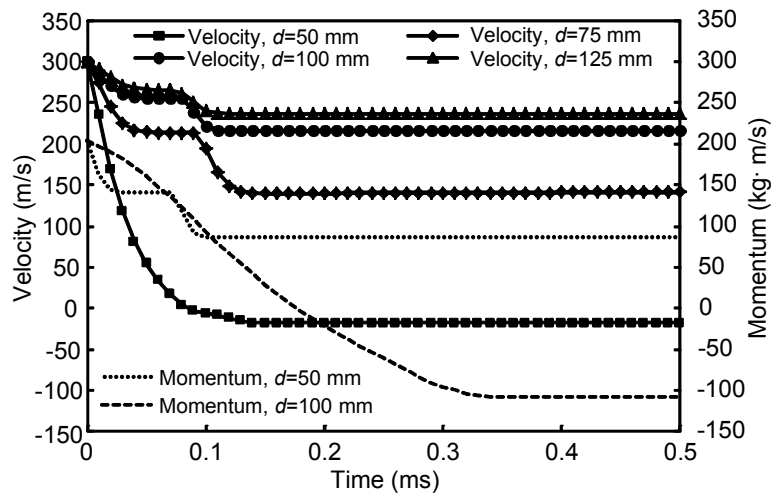

Fig. 9 Velocity and momentum of missile over time for various projectile diameters $(P=1.8 \mathrm{MPa})$

\subsection{Influence of internal pressure}

Figs. 10-13 demonstrate the influence of internal gas pressure. The diameters of the spherical projectiles are all $100 \mathrm{~mm}$. Fig. 10 shows the transverse deflection time history at the impact point for various gas pressures by a relatively low velocity projectile $(50 \mathrm{~m} / \mathrm{s})$. As shown in Fig. 10, all the missiles bounce back and the pipe walls vibrate due to the impact. It also can be seen from Fig. 10 that the deflection is relatively small for higher gas pressure pipes. Figs. 11 and 12 are the peak deflections and permanent de- flections, respectively, at the impact point for various internal pressures of pipes. As shown in Figs. 11 and 12 , the peak deflections and permanent deflections increase with the increase of impact velocity and decrease with the increase of internal pressure.

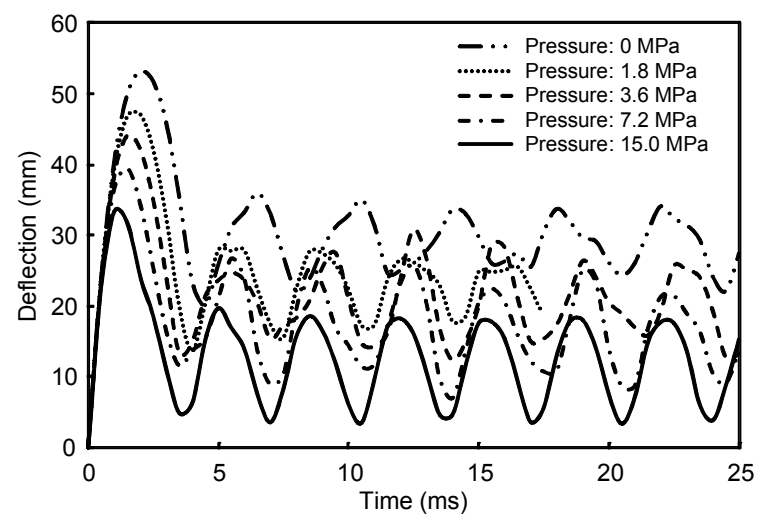

Fig. 10 Transverse deflection time history at the point of impact for various internal pressures

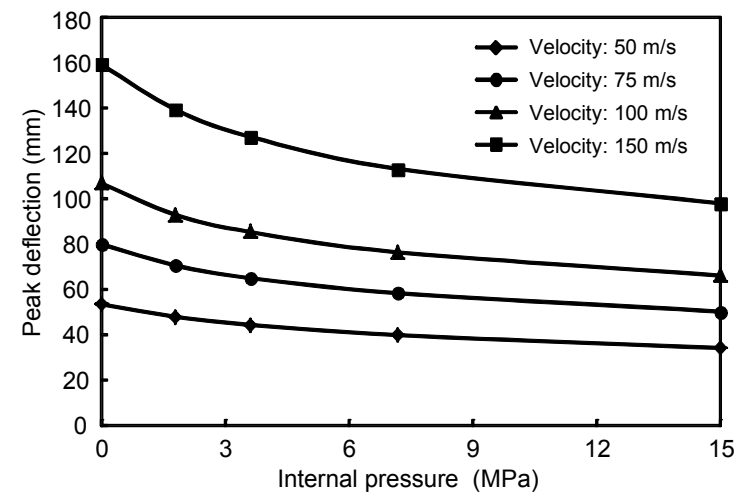

Fig. 11 Peak deflections at impact point for various internal pressures

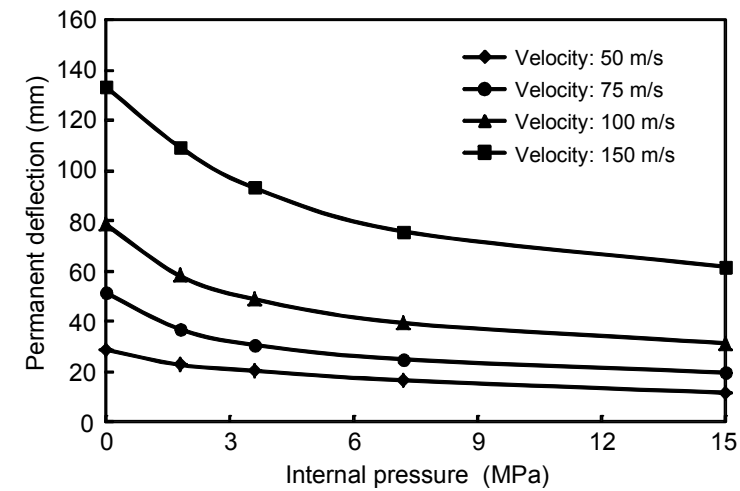

Fig. 12 Permanent deflections at impact point for various internal pressures 
Fig. 13 depicts the impact velocity over time for various internal pressures. Initially, the projectiles contact the front pipe wall and their velocities decrease. Some of the projectiles perforate the front wall and the velocities of these projectiles basically remain constant, until they reach the back wall. The velocities of projectiles will then decrease until they perforate, or rebound from the back pipe wall. The negative velocity of a projectile thus represents rebound. It can be seen from Fig. 13 that the projectile perforates the two pipe walls at pressure $15.0 \mathrm{MPa}$, while for pressures 7.2 and 3.6 MPa, the projectiles only perforate the front pipe wall and rebound at the back pipe wall. For the smaller pressures of 1.8 and $0 \mathrm{MPa}$, the projectiles rebound at the front pipe wall. This phenomenon indicates that increasing the internal pressure decreases the perforation resistance of the steel pipes when the impact velocity is larger than the crack limit velocity. For impacts without crack formation, the internal pressure increases the elastic resistance of the pipes and decreases the deformation.

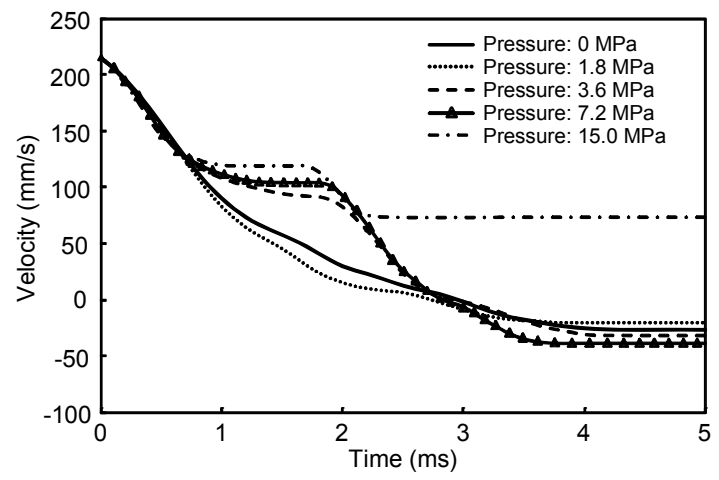

Fig. 13 Velocities variation during impacts for $100 \mathrm{~mm}$ spherical projectile (impact velocity is $216 \mathrm{~m} / \mathrm{s}$ )

\section{Conclusions}

Modeling pressure pipes subjected to highvelocity impacts is a complex problem that involves fluid-structure interaction, penetration, strain rate effect, etc. It is difficult to describe the complicated process by a simple analysis model and observe it by experimental techniques. In this paper, some valuable conclusions were obtained as follows:

1. An FE model was developed to simulate gas-filled steel pipes impacted by high-velocity projectiles. In the detailed FE analyses, the Johnson-
Cook model was used to simulate the dynamic behavior of steel due to strain hardening, strain-rate hardening, and thermal softening, and surface-based cavities were used to simulate the coupling between the pipe and the gas pressure. The numerical model was verified by the experimental results of Jones and Birch (1996) and Rosenberg and Forrestal (1988).

2. Some parameters, such as pipe wall thickness, missile nose shape, diameter of spherical missile, and internal pressure of the pipe, were investigated, and the parametric study indicated that greater wall thickness increases the impact-resistant capacity of the pipe, and it is easier for projectiles with small contact area and high momentum to perforate steel pipes. The internal pressure decreases the perforation resistance of pipes while increasing their elastic resistance toward impacts without crack formation.

3 . The numerical model reported in this paper provides reasonable estimates of the failure mode and the transverse deformation of pipes subjected to high-velocity impact loads, and it is helpful for the blast-resistant design of pressure pipes and other similar structures in an environment with an explosion risk.

\section{References}

ABAQUS, 2010. Abaqus 6.10: User Documentation. ABAQUS, Providence, RI, USA.

ASME (American Society of Mechanical Engineers), 2004. Welded and Seamless Wrought Steel Pipe, ASME B36.10M-2004. ASME, USA.

ASME (American Society of Mechanical Engineers), 2007. Gas Transmission and Distribution Piping Systems, ASME B31.8-2007. ASME, USA.

Ben-Dor, G., Dubinsky, A., Elperin, T., 2005. Ballistic impact: recent advances in analytical modeling of plate penetration dynamics - a review. Applied Mechanics Reviews, 58(6):355-370. http://dx.doi.org/10.1115/1.2048626

Børvik, T., Langseth, M., Hopperstad, O.S., et al., 1999. Ballistic penetration of steel plates. International Journal of Impact Engineering, 22(9-10):855-886. http://dx.doi.org/10.1016/S0734-743X(99)00011-1

Børvik, T., Hopperstad, O.S., Berstad, T., et al., 2002. Perforation of $12 \mathrm{~mm}$ thick steel plates by $20 \mathrm{~mm}$ diameter projectiles with flat, hemispherical and conical noses. Part II: numerical simulations. International Journal of Impact Engineering, 27(1):37-64. http://dx.doi.org/10.1016/S0734-743X(01)00035-5

Chase, M.W.Jr., 1998. NIST-JANAF Thermochemical Tables, 4th Edition. American Chemical Society, New York, USA.

Chen, K.S., Shen, W.Q., 1998. Further experimental study on the failure of fully clamped steel pipes. International Journal of Impact Engineering, 21(3):177-202. http://dx.doi.org/10.1016/S0734-743X(97)00083-3 
Corbett, G.G., Reid, S.R., Alhassani, S.T.S., 1990. Static and dynamic penetration of steel tubes by hemispherically nosed punches. International Journal of Impact Engineering, 9(2):165-190.

http://dx.doi.org/10.1016/0734-743X(90)90011-J

Gupta, N.K., Iqbal, M.A., Sekhon, G.S., 2006. Experimental and numerical studies on the behavior of thin aluminum plates subjected to impact by blunt- and hemisphericalnosed projectiles. International Journal of Impact Engineering, 32(12):1921-1944.

http://dx.doi.org/10.1016/j.ijimpeng.2005.06.007

Hancock, J.W., Mackenzie, A.C., 1976. On the mechanisms of ductile failure in high-strength steels subjected to multiaxial stress-states. Journal of the Mechanics and Physics of Solids, 24(2-3):147-160.

http://dx.doi.org/10.1016/0022-5096(76)90024-7

Johnson, G.R., Cook, W.H., 1983. A constitutive model and data for metals subjected to large strains, high strain rates and high temperatures. Proceedings of the 7th International Symposium on Ballistics, the Hague, the Netherlands, p.541-547.

Johnson, G.R., Cook, W.H., 1985. Fracture characteristics of three metals subjected to various strains, strain rates, temperatures and pressures. Engineering Fracture $\mathrm{Me}$ chanics, 21(1):31-48. http://dx.doi.org/10.1016/0013-7944(85)90052-9

Jones, N., Shen, W.Q., 1992. Theoretical study of the lateral impact of fully clamped pipelines. Proceedings of the Institution of Mechanical Engineers, Part E: Journal of Process Mechanical Engineering, 206(2):129-146. http://dx.doi.org/10.1243/pime_proc_1992_206_208_02

Jones, N., Birch, R.S., 1996. Influence of internal pressure on the impact behavior of steel pipelines. Journal of Pressure Vessel Technology, 118(4):464-471. http://dx.doi.org/10.1115/1.2842215

Jones, N., Birch, R.S., 2010. Low-velocity impact of pressurised pipelines. International Journal of Impact Engineering, 37(2):207-219.

http://dx.doi.org/10.1016/j.ijimpeng.2009.05.006

Jones, N., Birch, S.E., Birch, R.S., et al., 1992. Experimental study on the lateral impact of fully clamped mild steel pipes. Proceedings of the Institution of Mechanical Engineers, Part E: Journal of Process Mechanical Engineering, 206(2):111-127.

http://dx.doi.org/10.1243/pime_proc_1992_206_207_02

Liu, J.H., Francis, A., 2004. Theoretical analysis of local indentation on pressured pipes. International Journal of Pressure Vessels and Piping, 81(12):931-939. http://dx.doi.org/10.1016/j.ijpvp.2004.05.007

Lu, G.Y., Zhang, S.Y., Lei, J.P., et al., 2007. Dynamic responses and damages of water-filled pre-pressurized metal tube impacted by mass. International Journal of Impact Engineering, 34(10):1594-1601. http://dx.doi.org/10.1016/j.ijimpeng.2006.07.006

Nishida, M., Tanaka, K., 2006. Experimental study of perforation and cracking of water-filled aluminum tubes impacted by steel spheres. International Journal of Impact Engineering, 32(12):2000-2016. http://dx.doi.org/10.1016/j.ijimpeng.2005.06.010
Pantalé, O., Bacaria, J.L., Dalverny, O., et al., 2004. 2D and $3 \mathrm{D}$ numerical models of metal cutting with damage effects. Computer Methods in Applied Mechanics and Engineering, 193(39-41):4383-4399. http://dx.doi.org/10.1016/j.cma.2003.12.062

Rezaei, A., Verhelst, R., van Paepegem, W., et al., 2011. Finite element modelling and experimental study of oblique soccer ball bounce. Journal of Sports Sciences, 29(11): 1201-1213. http://dx.doi.org/10.1080/02640414.2011.587443

Rosenberg, Z., Forrestal, M.J., 1988. Perforation of aluminum plates with conical-nosed rods - additional data and discussion. Journal of Applied Mechanics, 55(1):236-238. http://dx.doi.org/10.1115/1.3173639

Shah, Q.H., 2011. Experimental and numerical study on the orthogonal and oblique impact on water filled pipes. International Journal of Impact Engineering, 38(5):330338.

http://dx.doi.org/10.1016/j.ijimpeng.2010.12.001

Yang, J.L., Lu, G.Y., Yu, T.X., et al., 2009. Experimental study and numerical simulation of pipe-on-pipe impact. International Journal of Impact Engineering, 36(10-11): 1259-1268.

http://dx.doi.org/10.1016/j.ijimpeng.2009.05.001

Zhao, Y., Wang, Z.Y., He, Z.G., 2014. Numerical study of CFRP-bonded pressure pipes subject to impact load. Applied Mechanics and Materials, 602-605:432-437. http://dx.doi.org/10.4028/www.scientific.net/AMM.602605.432

\section{中文概要}

题 目: 高速冲击作用下压力管道力学行为的数值研究

目 的: 压力管道是海洋石油化工等领域的常用构件, 但 经常受到泄漏、爆炸和冲击等事件的威胁。本文 旨在探讨压力管道在高速冲击作用下的力学响 应及失效机理。

创新点: 1. 开发考虑金属大变形和高应变率的非线性模 型, 通过基于表面的流体腔模型来模拟管道气体 和管道的耦合作用, 简化计算模型, 提高计算效 率; 2. 通过非线性有限元模型, 对管道高速冲击 响应的影响因素进行研究分析。

方 法: 1. 采用 Johnson-Cook 模型模拟金属的大应变及大 应变率; 2. 采用基于表面的流体腔模拟管道与内 部气体的耦合作用; 3. 与实验结果对比验证模型 的准确性; 4. 分析影响管道抗冲击性能的参数。

结 论: 1. 管道壁厚显著影响管道的抗冲击性能; 2 . 在相 同冲量下, 冲击头与管道的接触面积越小, 管道 越容易被穿透; 3. 在管道受到冲击时, 管道内压 越大, 管道抗穿透能力越小; 4 . 在管道未被破坏 时, 管道内压能够增加管道的弹性, 减小管道受 冲击后的凹陷深度。

关键词：高速冲击；流固耦合；抗冲击性；数值模拟 